\title{
Comparison between methyldopa and combination of methyldopa and nifedipine in terms of mean change in blood pressure in pregnancy induced hypertension
}

\author{
BILQEES AKHTAR MALIK ${ }^{1}$, SHAHZAD BASHIR MOMINA ${ }^{2}$, TAZEEN ASHRAF ${ }^{3}$ \\ ${ }^{1}$ Assistant Professor, Department of Obstetrics \& Gynecology, Combined Military Hospital Bahawalpur \\ ${ }^{2}$ Classified Gynaecologist, Assistan Professor, Combine military Hospital Chhor / National University of Medical Science (NUMS) Rawalpindi \\ ${ }^{3}$ Specialist Obstetrics and Gynecology, Evercare Hospital Lahore \\ Correspondence to: Dr. Bilqees Akhtar Malik, Email: Bilqeesmalik123@outlook.com, Cell: 03218163294
}

\begin{abstract}
Objective: Comparison between Methyldopa and combination of Methyldopa and Nifedipine in terms of mean change in blood pressure in pregnancy induced hypertension.

Material and methods: This randomized controlled trial was conducted at Department of Obstetrics and Gynecology, Combined Military Hospital Bahawalpur from February 2020 to August 2020 over the period of 6 months. Total 80 patients with pregnancy induced hypertension as per operational definition having age 20-40 years and having gestational age $\geq 20$ weeks assessed on LMP were selected.

Results: Mean age of the patients was $30.81 \pm 5.670$ years, mean age of patients of group A was $31.50 \pm 5.809$ years and mean age of group B was $30.13 \pm 5.515$ years. Mean gestational age was $30.17 \pm 5.981$ weeks, mean gestational age of patients of group A was $29.70 \pm 6.329$ weeks and mean gestational age of patients of group B was $30.65 \pm 5.65$ weeks. In group A, mean diastolic blood pressure was decrease from $101.2250 \pm 4.97938$ to $84.5000 \pm 3.26599$ and in group $B$ from $107.7750 \pm 7.18434$ to $82.5000 \pm 2.25320$. Comparison of mean decrease in diastolic blood pressure between group A (High dose Methyldopa) and group B (Low dose Low dose Methyldopa with Nifedipine) was done. Mean decrease in diastolic blood pressure in group A was $16.72 \pm 3.935$ and in group B was $25.28 \pm 6.876$. Statistically significant difference of mean decrease in diastolic blood pressure between the both groups was noted with p value 0.000 .

Conclusion: Results of this study showed that Low dose Methyldopa with Nifedipine combination is more effective as compared to High dose Methyldopa to reduce diastolic blood pressure in pregnant women suffering from pregnancy induced hypertension.

Keywords: Diastolic blood pressure, Methyldopa, Nifedipine, Pregnancy induced hypertension, Systolic blood pressure
\end{abstract}

\section{INTRODUCTION}

Pregnancy induced hypertension is among the common medical problem affecting upto $15-20 \%$ of pregnancies and cause of significant maternal and perinatal mortality and morbidity. ${ }^{1}$ Pregnancy induced hypertension ultimately leads to critical condition like preeclampsia and life threatening condition like Eclampsia and HELLP Syndrome. ${ }^{2}$ So it is necessary to treat pregnancy induced hypertension. ${ }^{3}$ Numerous drugs including Methyldopa, Nifedipine, Hydralazine, Labetelol have been studied for its control. ${ }^{4}$ Methyldopa is among the preferred drugs for control of pregnancy induced hypertension as its safety during pregnancy has long been established ${ }^{5}$ but it controls blood pressure in about 4 to 6 hours and has side effects of over sedation at onset and impaired mental concentration and lassitude at high doses. ${ }^{6}$ Nifedipine is second line therapy for control of pregnancy induced hypertension. ${ }^{7}$ Nifedipine has rapid onset, longer duration of action and good oral bioavailability ${ }^{8}$ but has side effects at high dosage. .,9 $^{2}$

Poly pharmacy is preferred over monotherapy in control of hypertension due to adverse effects associated with monotherapy and different mechanism of action of each drug. Pharmacokinetics of both drugs show that effects of both drugs are balanced. ${ }^{6}$

Received on 17-02-2021

Accepted on 15-06-2021
Both drugs have been studied separately and their relative efficacy has been compared, but limited literature has been found comparing the combination therapy of both drugs at low dose with high dose of first line monotherapy. So if low dose is found to be more promising than the same will be used and advocated in patients with pregnancy induced hypertension. This will further cut down the cost of medication and will benefit poor patient of our community.

OPERATIONAL DEFINITION

Pregnancy induced hypertension is defined as raised blood pressure equal to or more than $160 / 100$ at two separate occasions, four hours apart after 20 weeks of gestation assessed on last menstrual period.

High dose Monotherapy when one drug is used for treatment, selected monotherapy is Tab. Methyldopa $750 \mathrm{mg}$ thrice daily.

Low dose Combination therapy when two or more than two drugs are used for treatment, selected combination therapy is Tab. Methyldopa $250 \mathrm{gm}$ thrice daily with Tab. Nifedipine $10 \mathrm{gm}$ twice daily.

Mean change in diastolic blood pressure was recorded in admitted patients at start of treatment and after 96 hours of start of treatment, these readings was recorded in diastolic blood pressure in $\mathrm{mmHg}$.

METHODS AND MATERIAL

This randomized controlled trial was conducted at Department of Obstetrics and Gynecology, Combined 
Military Hospital Bahawalpur from February 2020 to August 2020 over the period of 6 months. Total 80 patients with pregnancy induced hypertension as per operational definition having age 20-40 years and having gestational age $\geq 20$ weeks assessed on LMP were selected.

Patients with cardiac disease and diabetes mellitus (on history), patients with renal and thyroid disease (on history) and patients taking any other antihypertensive therapy were excluded from the study.

Study is approved by the ethical committee of the institution and written informed consent was taken from every patient.

Selected patients were divided into two study group A and B. In study group, Tab. Methyldopa 750mg thrice daily was given and in group $B$, Methyldopa $250 \mathrm{gm}$ thrice daily with Tab. Nifedipine $10 \mathrm{gm}$ twice daily were given.

Admitted patients were monitored by recording blood pressure. Fetal monitoring was done by clinical recording of fetal heart sounds and CTG.

Outcome measures was diastolic blood pressure at the start of treatment, and blood pressure was measured 4 hours apart after start of treatment during daytime and 6 hours apart during night time and mean of diastolic blood pressure was calculated at 48 hours and then at 96 hours. Data was collected from patient file on daily basis from daily maintained blood pressure chart and was entered on Performa.

Data was collected in from of variables and was entered and analysis was done by SPSS-17.

Mean and SD was calculated for age, gestational age mean decrease in diastolic blood pressure for both groups. Student $t$ test was applied to detect difference between the mean decrease in diastolic blood pressure of both treatment groups. Stratification for age, gestational age was done and post stratification student t test was applied to compare the mean decrease in diastolic blood pressure. $P$-value of less than and equal to 0.05 was taken as significant.

\section{RESULTS}

Mean age of the patients was $30.81 \pm 5.670$ years, mean age of patients of group $A$ was $31.50 \pm 5.809$ years and mean age of group $B$ was $30.13 \pm 5.515$ years.

Mean gestational age was $30.17 \pm 5.981$ weeks, mean gestational age of patients of group A was $29.70 \pm$ 6.329 weeks and mean gestational age of patients of group B was $30.65 \pm 5.650$ weeks.

In group $A$, mean diastolic blood pressure was decrease from $101.2250 \pm 4.97938$ to $84.5000 \pm 3.26599$ and in group B from $107.7750 \pm 7.18434$ to $82.5000 \pm$ 2.25320. (Table 1)

Table 1: Mean diastolic blood pressure before and after treatment of both groups

\begin{tabular}{|c|c|c|c|c|}
\hline \multirow{2}{*}{ Study Group } & \multicolumn{2}{|c|}{ Mean diastolic BP before treatment } & \multicolumn{2}{|c|}{ Mean diastolic BP after treatment } \\
\hline & Mean & SD & Mean & SD \\
\hline A & 101.2250 & 4.97938 & 84.5000 & 3.26599 \\
\hline$B$ & 107.7750 & 7.18434 & 82.5000 & 2.25320 \\
\hline
\end{tabular}

Table 2: Comparison of mean decrease in diastolic blood pressure between group A and B

\begin{tabular}{|l|l|l|l|l|}
\hline Group & $\mathrm{n}$ & Mean & Std. Deviation & P Value \\
\hline $\begin{array}{l}\text { A } \\
\text { High dose Methyldopa }\end{array}$ & 40 & 16.72 & 3.935 & \multirow{2}{*}{0.000} \\
\hline $\begin{array}{l}\text { B } \\
\text { Low dose Methyldopa with Nifedipine }\end{array}$ & 40 & 25.28 & 6.876 & \\
\hline
\end{tabular}

Table 3: Comparison of mean decrease in diastolic blood pressure between group A and B for age groups

\begin{tabular}{|c|c|c|c|c|}
\hline Group & $\mathrm{n}$ & Mean & Std. Deviation & $\mathrm{P}$ Value \\
\hline \multicolumn{5}{|l|}{ Age group $20-30$ years } \\
\hline $\begin{array}{l}\text { A } \\
\text { High dose Methyldopa }\end{array}$ & 17 & 17.41 & 4.214 & \multirow{2}{*}{0.001} \\
\hline $\begin{array}{l}\text { B } \\
\text { Low dose Methyldopa with Nifedipine }\end{array}$ & 22 & 23.91 & 6.640 & \\
\hline \multicolumn{5}{|l|}{ Age group $31-40$ years } \\
\hline $\begin{array}{l}\text { A } \\
\text { High dose Methyldopa }\end{array}$ & 23 & 16.22 & 3.729 & \multirow{2}{*}{0.000} \\
\hline $\begin{array}{l}\text { B } \\
\text { Low dose Methyldopa with Nifedipine }\end{array}$ & 18 & 26.94 & 6.975 & \\
\hline
\end{tabular}

Table 4

\begin{tabular}{|c|c|c|c|c|}
\hline Group & $\mathrm{n}$ & Mean & Std. Deviation & P Value \\
\hline \multicolumn{5}{|l|}{ Gestational age $20-30$ weeks } \\
\hline $\begin{array}{l}\text { A } \\
\text { High dose Methyldopa }\end{array}$ & 21 & 17.14 & 4.078 & \multirow[b]{2}{*}{0.000} \\
\hline $\begin{array}{l}\text { B } \\
\text { Low dose Methyldopa with Nifedipine }\end{array}$ & 19 & 23.79 & 6.680 & \\
\hline \multicolumn{5}{|l|}{ Gestational age 31-40 weeks } \\
\hline $\begin{array}{l}\text { A } \\
\text { High dose Methyldopa }\end{array}$ & 19 & 16.26 & 3.827 & \multirow{2}{*}{0.000} \\
\hline $\begin{array}{l}\text { B } \\
\text { Low dose Methyldopa with Nifedipine }\end{array}$ & 21 & 26.62 & 6.932 & \\
\hline
\end{tabular}


Comparison of mean decrease in diastolic blood pressure between group A (High dose Methyldopa) and group B (Low dose Low dose Methyldopa with Nifedipine) was done. Mean decrease in diastolic blood pressure in group A was $16.72 \pm 3.935$ and in group B was $25.28 \pm$ 6.876. Statistically significant difference of mean decrease in diastolic blood pressure between the both groups was noted with $p$ value 0.000 . (Table 2)

Two age groups were created which are age group 20-30 years and age group 31-40 years. In age group 2030 years, mean decrease in diastolic blood pressure in study group A was $17.41 \pm 4.214$ and in group $B$ was $23.91 \pm 6.640$. Difference was statistically significant between the both groups with $p$ value 0.001 In age group 31-40 years, mean decrease in diastolic blood pressure in study group A was $16.22 \pm 3.729$ and in group B was $26.94 \pm 6.975$. Difference was statistically significant between the both groups with $p$ value 0.000 (Table 3)

Two groups were created according to gestational age, which are 20-30 weeks and 31-40 weeks. In 20-30 weeks gestational age group, mean decrease in diastolic blood pressure in study group A was $17.14 \pm 4.078$ and in group B was $23.79 \pm 6.680$. Difference was statistically significant between the both groups with $p$ value 0.000 In 31-40 weeks gestational age group, mean decrease in diastolic blood pressure in study group A was $16.26 \pm$ 3.827 and in group $B$ was $26.62 \pm 6.932$. Difference was statistically significant $(P=0.000)$ between the both groups. (Table 4)

\section{DISCUSSION}

Blood pressure fluctuation and its maintenance during pregnancy is a challenging clinical problem to clinicians. The approach to evaluation and treatment differs substantially from non-pregnant women. Anti-hypertensive agents diminish the blood pressure and antihypertensive therapy in pregnancy induced hypertension is to prevent complications due to hypertension while advancement of pregnancy. The most commonly prescribed antihypertensive drugs are adrenergic receptor alpha-2 agonists such as Methyldopa, calcium channel blocker Nifedipine and Labetol. ${ }^{10-11}$

In present study, in group $A$, mean diastolic blood pressure was decrease from $101.2250 \pm 4.97938$ to $84.5000 \pm 3.26599$ and in group B from $107.7750 \pm$ 7.18434 to $82.5000 \pm 2.25320$ after treatment. Comparison of mean decrease in diastolic blood pressure between group A (High dose Methyldopa) and group B (Low dose Low dose Methyldopa with Nifedipine) was done. Mean decrease in diastolic blood pressure in group A was 16.72 \pm 3.935 and in group B was $25.28 \pm 6.876$. Statistically significant difference of mean decrease in diastolic blood pressure between the both groups was noted with $p$ value 0.000 .

In one study by Jayasudha et al, ${ }^{12}$ blood pressure was decrease from $96 \pm 6.21$ to $82 \pm 7.14$ managed with methyldopa and in combination group (methyldopa and nifedipine) blood pressure was decreased from $112.5 \pm$ 11.05 to $85 \pm 6.88$.
Togarikar et al $^{13}$ reported use of anti-hypertensive drugs had reduced SBP and DBP significantly. After the use of methyldopa, DBP reduced from $99.6 \pm 8.8$ to 96.17 \pm 6.4 .

Another study by Bharathi $\mathrm{KN}$ et al ${ }^{14}$ stated both methyldopa and nifedipine showed equal effect on reducing the blood pressure. In another study, it is found that the use of anti-hypertensive drugs had reduced the systolic and diastolic blood pressure markedly. Diastolic BP before and after treatment were $100.07 \pm 11.83 \mathrm{mmHg}$ and 85.19 $\pm 8.52 \mathrm{mmHg}$ respectively after use of methyldopa. ${ }^{15}$

\section{CONCLUSION}

Results of this study showed that Low dose Methyldopa with Nifedipine combination is more effective as compared to High dose Methyldopa to reduce diastolic blood pressure in pregnant women suffering from pregnancy induced hypertension.

\section{REFERENCES}

1. Magee LA, Abalos E, von Dadelszen $P$, Sibai B, Easterling $T$, Walkinshaw $S$ et al. How to manage hypertension in pregnancy effectively. Br J Clin Pharmacol. 2011Sep;72(3):394-401

2. Lamarca B. Endothelial dysfunction. An important mediator in the pathophysiologh of hypertension during pre-eclampsia. Minerva Ginecol. 2012 Aug:64(4):309-20

3. Ghanem FA, Movahed A. Use of antihypertensive drugs during pregnancy and lactation. Gardiovasc Ther. 2008 Spring:26(1):38-49.

4. Vest AR, Cho LS. Hypertension in pregnancy. Cardiol Clin. 2012 Aug: 30 (3):407-23

5. Jeff M. Denney, Troy Flint Porter, D. Ware Branch. High Risk Pregnancy. Autoimmune Diseases. In: David James, Philip J. Steer, Carl P. Weiner, Bernard Gonik editors, High Risk Pregnancy, 4th ed. St. Louis: Saunders, An Imprint of Elsevier; 2010. p.783.

6. Katzung BG. Basic \& clinical pharmacology. New York [u.a.: McGraw-Hill Medical; 2012.

7. De Souza AR, Amorim MR, Costa AR. Nifedipine antihypertensive treatment effects in pre-eclampsia. Acta Med Port. 2008 Jul-aug:21 (4):351-8

8. Rezaei Z, Sharbaf FR, Pourmojieb M, Youefzadeh-Fard Y, Motevalian M, Khazaeipour Z et al. Comparison of the efficacy of nifedipine and hydralazine in hypertensive crisis in pregnancy. Acta Med Iran. 2011:49(11):701-6.

9. Khan K, Zamora J, Lamont RF, Van Geijn Hp H, Svare J, SantosJorge $\mathrm{C}$ et al. Safety concerns for the use of calcium channel blockers in pregnancy for the treatment of spontaneous preterm labour and hypertension: a systematic review and meta- regression analysis. J Matern Fetal Nenatal Med. 2010 Sep:23(9):1030-8.

10. Abalos E, Duley L, Steyn DW, Henderson-smart DJ. Antihypertensive drug therapy to mild to moderate hypertension during pregnancy. Cochrane Library. 2003;1.

11. Cvijic M, Horvat M, Jernejcic P, Verdenik I, Geršak K. Analysis of the intake of drugs used in hypertensive disorders during pregnancy. Zdrav Vestn. 2010;79:412-8.

12. Jayasutha J, Ismail AM, Senthamarai R. Evaluation on efficacy of Methyldopa monotherapy and combination therapy with Nifedipine in pregnancy-induced hypertension. Der Pharmacia Lettre. 2011;3:3837.

13. Togarikar SM. Efficacy of methyldopa versus nifedipine in mild and severe pregnancy induced hypertension. International Journal of Reproduction, Contraception, Obstetrics and Gynecology. 2017 Sep 23:6(10):4544.

14. Bharathi KN, Prasad KVSRG, Jagannath P, Nalini KS. Comparison of Nifedipine with Methyldopa for Control of Blood Pressure in Mild to Moderate Pregnancy Induced Hypertension. J Clin Diagnos Res. 2010;4(3):2406-9.

15. Venkateshwaramurthy $\mathrm{N}$, Christy $\mathrm{J}$, Perumal $\mathrm{P}$. Study on antihypertensives in pre-eclampsia. Asian Journal of Pharmaceutical and Clinical Research. 2012;201(5):3. 